Brit. Heart F., 1966, 28, 829.

\title{
Significance of S Waves in Limb Leads II and III of the Electrocardiogram
}

\author{
WILLIAM EVANS
}

From the Cardiac Department, The London Hospital, London E.1

In a paper by Davies and Evans (1960), the electrocardiographic finding of an $S$ wave that exceeds the $R$ wave in amplitude in leads II and III when the $S$ is absent in lead I was regarded as meaning unexceptionally a lesion in the anterolateral sector of the left ventricle. The authors conceded that insistence on the $S$ in lead II of this distinctive cardiogram being greater in amplitude than the $R$ wave was arbitrary, fixing as it did the mean axis at $-30^{\circ}$ or farther to the left, and that an $S$ wave shorter than the $R$ in this lead might also be evidence of a myocardial fault, but they chose to limit the scope of their inquiry to the significance of the cardiogram which showed the more obvious disparity between the size of the two waves.

The present paper describes an investigation which examines the significance of a cardiogram in which the $S$ wave, absent in lead I, appears in leads II and III in any amplitude.

Testing the competency of some obvious electrocardiographic deformity to tell the presence of a myocardial injury is not a difficult task, for such a deformity is seldom found in asymptomatic subjects, and necropsy always demonstrates the myocardial lesion which has produced the cardiographic fault. To test the reliability of a lesser electrocardiographic deformity in connoting a myocardial lesion is more difficult, because such a small irregularity in the tracing, indicating as it does a young injury, may be found in apparently healthy subjects years ahead of symptoms and of the appearance of more obvious cardiographic signs. Moreover, the opportunity to examine the heart at necropsy in search of a causative lesion seldom materializes until an older age when the lesser changes in the tracing may have been obscured by others resulting from extension of the area of injury.

In this event, the responsibility laid on one who

Received January 14, 1966. undertakes to appraise the value of a lesser electrocardiographic sign in the detection of a myocardial flaw is heavy, for he must guard zealously against apportioning to any uncomplaining subject the stigma of having an abnormality of unproven significance.

\section{The INVESTIGATION}

The electrocardiogram was specially examined in 100 consecutive patients showing an S wave in leads II and III in the absence of an $S$ in lead I. The patients had attended either on account of material symptoms like cardiac pain, because of trivial complaints like palpitation, or they had sought a routine medical examination. Each was examined clinically and by cardioscopy, and specially questioned about a history of chest pain. Those found to have left ventricular hypertrophy from either systemic hypertension or aortic valve disease, and those with myocardiopathy were excluded from the series.

In addition to the three standard limb leads, the cardiogram also included leads IIIR (lead III taken during deep inbreathing), CR1, CR4, and CR7; whenever the $R$ wave was absent or diminutive in CR1, lead CR2 was recorded as well. The opportunity to examine a subsequent cardiogram happened in only 10 instances, for none of the asymptomatic patients was told that a disfigurement was suspected in the electrocardiogram.

The patients were then allocated to one of three groups based on the amplitude of the $S$ wave in lead II. The first group consisted of 21 patients in whom the $S$ was greater than the $R$ wave (Fig. 1A). The second group comprised 37 patients in whom the $S$, though less than the $R$, exceeded $1.0 \mathrm{~mm}$. in amplitude (Fig. 1B). The third group were 42 patients in whom the $S$ wave measured $1.0 \mathrm{~mm}$. or less (Fig. 1C).

The patients were also arranged in three groups depending on the extent to which the $R / S$ ratio in lead III changed during deep inspiration as recorded in IIIR. This classification permitted an estimate of the significance of the electrocardiographic sign under probation, in relation to the stability of the $S$ in lead III, for 829 


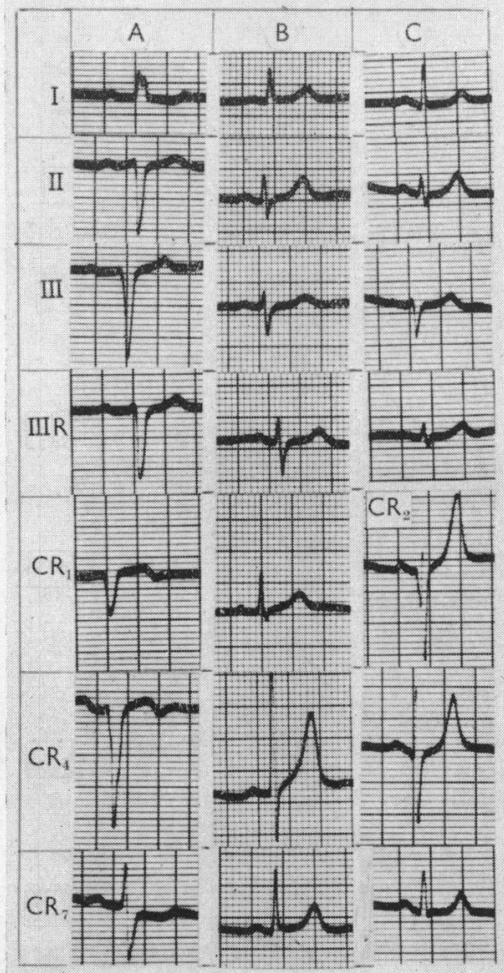

FIG. 1.-Three degrees of $S$ wave amplitude in lead II. (A) $S$ greater than $R$. (B) $S$ less than $R$, but greater than $1.0 \mathrm{~mm}$. (C) $S$ wave of $1.0 \mathrm{~mm}$. Other signs of cardiac infarction present in (A) and (C), but not in (B) taken from a man aged 73 with cardiac-like pain.

there were 58 patients in whom the $S$ wave was greater than $R$ in leads III and IIIR (Fig. 2A). In the second group there were 26 cases in whom the $S$ was greater than the $R$ wave in lead III, but less than $R$ in IIIR (Fig. 2B). In the third group, comprising 16 patients, the $S$ wave was less than $R$ in both III and IIIR (Fig. 2C).

\section{ANALYSIS OF FINDINGS}

Appraisal of the value of the electrocardiographic deformity under review in the detection of a small myocardial lesion might be best made by following the progress of individual patients who presented it. In the meantime, the dearth of electrocardiograms recorded in asymptomatic subjects at an early age prevents an appraisal of the changes based on such a premise. Moreover, repeated electrocardiography in young uncomplaining subjects with a small fault in the tracing is loaded with the risk of creating a cardiac neurosis.

The recording of a post-exercise electrocardiogram, though sometimes carried out, was not considered useful in those who showed this probationary sign in the absence of proven changes of

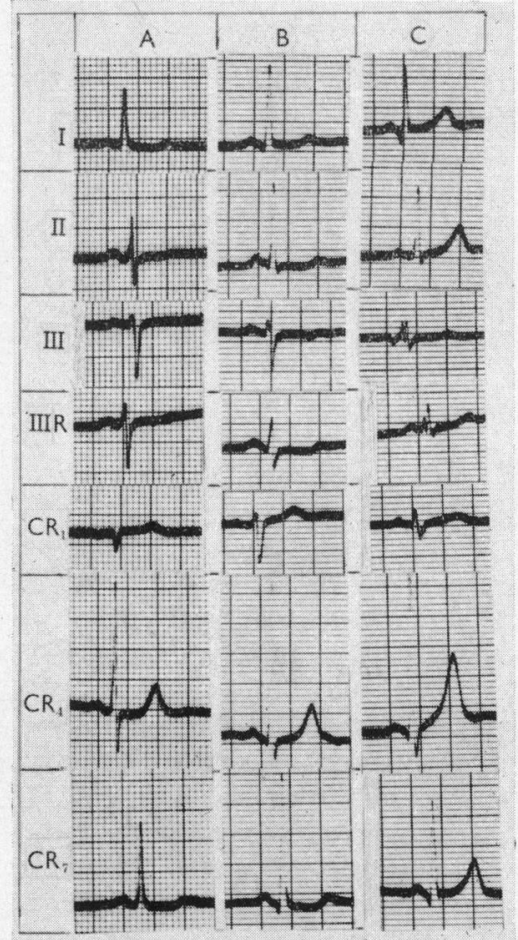

Fig. 2.-Three degrees of true $S$ wave amplitude in lead III, determined from its size in IIIR. (A) $S$ greater than $R$ in III and IIIR. (B) $S$ greater than $R$ in III, but less than $R$ in IIIR. (C) $S$ less than $R$ in both III and IIIR leads. Other signs of cardiac infarction (S-T depression in leads I, CR4 and CR7 in (A), and in I, II, IIIR, and CR7 in (B)), are absent in

(C) taken from a man aged 70 with cardiac-like pain.

myocardial disease, for a negative result in these circumstances, where the lion part of the coronary circulation was intact, would not justify a conclusion that the suspected myocardial flaw did not exist.

Accordingly, the two circumstances that helped most to gauge the significance of the electrocardiographic sign under review were the presence of cardiac pain, and/or of other changes in the tracing already accepted as meaning a myocardial lesion, and which themselves were expected to be small in those in whom cardiac pain had not in the meantime set in. The presence of supporting electrocardiographic signs rather than a history of chest pain, was regarded as the more reliable evidence that the probationary sign stood for a flaw in the myocardium.

Association of Cardiac Pain. Pain, which descriptively resembled cardiac pain, was present in 56 of the 100 patients, but in 4 of them the symptom occurred in the absence of significant supporting abnormal electrocardiographic signs, and the pain 


\section{TABLE I}

SIGNIFICANCE OF $S$ WAVE AMPLITUDE IN LEAD II JUDGED BY PRESENCE OF CARDIAC PAIN, AND BY ASSOCIATION OF MATERIAL ELECTROCARDIOGRAPHIC CHANGES, IN 100 CASES SHOWING THIS SIGN

\begin{tabular}{|c|c|c|c|c|c|}
\hline $\begin{array}{l}\text { Amplitude } \\
\text { of S } \\
\text { in lead II }\end{array}$ & $\begin{array}{c}\text { Mean } \\
\text { age } \\
\text { (yr.) }\end{array}$ & $\begin{array}{c}\text { Supporting } \\
\text { ECG signs } \\
\text { and } \\
\text { cardiac } \\
\text { pain }\end{array}$ & $\begin{array}{l}\text { Supporting } \\
\text { ECG signs } \\
\text { without } \\
\text { chest pain }\end{array}$ & $\begin{array}{c}\text { Chest } \\
\text { pain } \\
\text { without } \\
\text { support- } \\
\text { ing } \\
\text { ECG } \\
\text { signs }\end{array}$ & $\begin{array}{c}\text { Both } \\
\text { chest } \\
\text { pain and } \\
\text { support- } \\
\text { ing } \\
\text { ECG } \\
\text { signs } \\
\text { absent }\end{array}$ \\
\hline Greatest & 59 & 13 & 6 & 0 & 2 \\
\hline $\begin{array}{l}(21) \\
\text { Lesser }\end{array}$ & 55 & 17 & 15 & 1 & 4 \\
\hline $\begin{array}{l}\text { Least } \\
\text { (42) }\end{array}$ & 48 & 22 & 9 & 3 & 8 \\
\hline
\end{tabular}

Greatest: $\mathbf{S}$ greater than $\mathbf{R}$. Lesser : $\mathbf{S}$ less than $\mathbf{R}$, but greater than $1.0 \mathrm{~mm}$. Lesser: $S$ wave measuring $1.0 \mathrm{~mm}$. or less.

was not, therefore, regarded as having a cardiac source.

When the incidence of true cardiac pain, i.e. characteristic pain with an accepted abnormality in the electrocardiogram, was considered in relation to the amplitude of the S wave in lead II, there appeared to be no such association, for in each of the three groups arranged in regard to the size of $S$, the incidence was about the same, namely 13 out of 21 when it was greatest, 17 out of 37 when it was less, and 22 out of 42 where the $S$ wave was least (Table I).

Similarly, when the incidence of true cardiac pain was considered in relation to the amplitude of the $S$ wave in leads III and IIIR, there appeared to be no such correlation, for in the three groups arranged in regard to the stability of the $S$ wave amplitude in lead III, the incidence was not dissimilar, namely 34 out of 58 when it was greatest, 12 out of 26 when it was less, and 7 out of 16 when it was least stable (Table II).

None of the 100 patients in the series was invited to attend for re-examination, but 10 of them returned either on account of the onset of chest pain, or merely because they wished to have further reassurance about their health. In 5 of them where pain had been absent at the first examination, the symptom had set in before the second attendance in 3 ; in 2 an increase in the amplitude of the $S$ wave had taken place, and in the third there was accentuation of associated significant electrocardiographic signs. Pain continued to be absent in the other 2 patients.

Supporting Electrocardiographic Signs. Associated changes in the electrocardiogram indicative of a fault in the myocardium were present in 82 of the
TABLE II

SIGNIFICANCE OF S WAVE AMPLITUDE IN LEAD III (DEDUCED FROM AMPLITUDE OF S IN IIIR) JUDGED BY PRESENCE OF CARDIAC PAIN, AND/OR SUPPORTING MATERIAL ELECTROCARDIOGRAPHIC CHANGES

\begin{tabular}{c||c|c|c|c}
\hline $\begin{array}{c}\text { Stability of S } \\
\text { wave amplitude } \\
\text { in lead III }\end{array}$ & $\begin{array}{c}\text { Supporting } \\
\text { ECG signs } \\
\text { and } \\
\text { cardiac } \\
\text { pain }\end{array}$ & $\begin{array}{c}\text { Supporting } \\
\text { ECG signs } \\
\text { without } \\
\text { chest pain }\end{array}$ & $\begin{array}{c}\text { Chest pain } \\
\text { without } \\
\text { supporting } \\
\text { ECG signs }\end{array}$ & $\begin{array}{c}\text { Both chest } \\
\text { pain and } \\
\text { supporting } \\
\text { ECG signs } \\
\text { absent }\end{array}$ \\
\hline $\begin{array}{c}\text { Greatest } \\
\text { (58) } \\
\begin{array}{c}\text { Lesser } \\
(26) \\
\text { Least } \\
(16)\end{array}\end{array}$ & 34 & 20 & 2 & 2 \\
\hline
\end{tabular}

Greatest: $S$ greater than $R$ in III and IIIR. Lesser: $S$ greater than $R$ in III, but less than $R$ in IIIR. Least: $S$ less than $R$ in both III and IIIR leads.

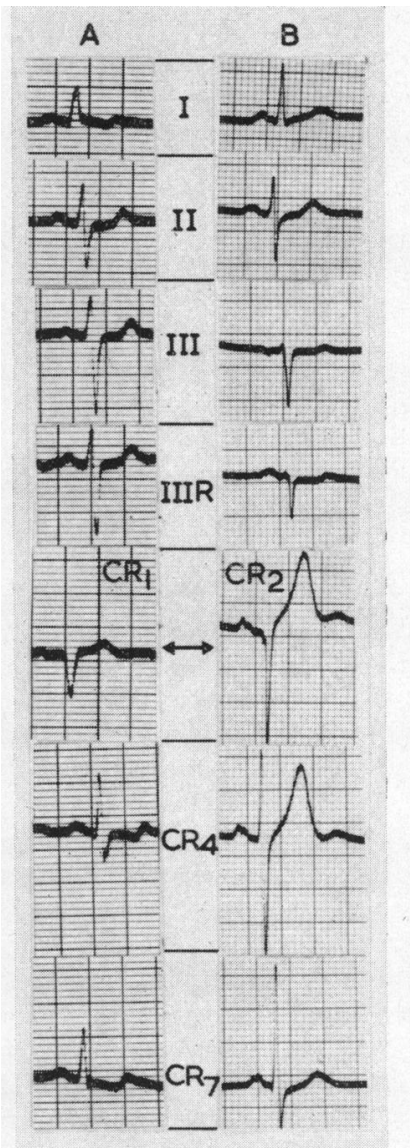

Fig. 3.-S and $R$ waves of equal amplitude in lead II in two patients with other signs of cardiac infarction. (A) Inversion of $T$ wave in lead I, CR4, and CR7, from a man aged 55 with cardiac pain. (B) Deep $Q$ wave in CR2, and low blunt $T$ waves in leads I and CR7, from a man of 76 years who had no cardiac pain. 
100 patients (Fig. 3), and in 52 of these cardiac pain was also present. In 18 the electrocardiographic deformity, here submitted to probation, was a lone sign (Fig. 4); in 4 of these there was chest pain, but in the absence of other significant changes in the tracing, it was not accepted as meaning true cardiac pain.

As expected the incidence of supporting electrocardiographic signs bore some relation to the amplitude of the S wave in lead II, so that they were present in 19 of 21 patients in whom the $S$ was greater than $R$, in 32 of the 37 in whom the $S$, though less than $R$, measured more than $1.0 \mathrm{~mm}$., and in 31 of the 42 in whom the $S$ was less than $1.0 \mathrm{~mm}$.

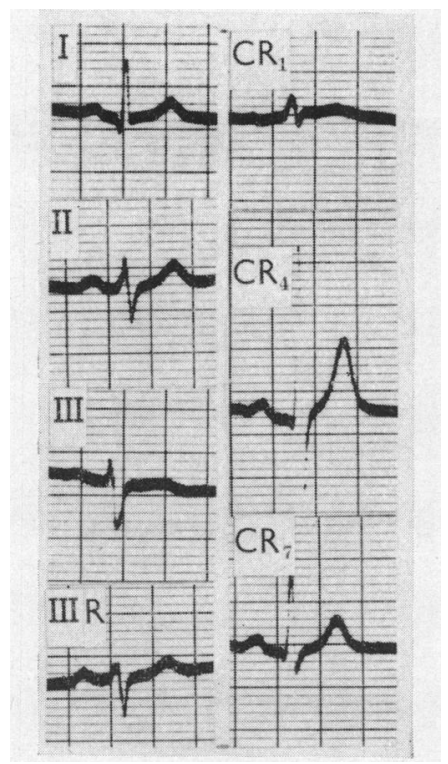

FIG. 4.-Deep $S$ waves in leads II and III in a man aged 46 with chest pain, but without other supporting signs of cardiac infarction.

When the incidence of associated material electrocardiographic signs was related to the different degrees of amplitude of the S wave in lead III, and especially its stable amplitude, judged by its size in IIIR, it was found that whereas such signs were present in 54 of the 58 patients in whom the $S$ was greater than the R wave in both leads III and IIIR, and in 22 of the 26 patients in whom the $S$ was greater than R in III, but less than R in IIIR, they were only present in 7 of the 16 patients in whom the $S$ was less than $R$ in both III and IIIR (Table II).

In the 10 patients who reported back for reexamination, the tracing was unchanged in 4 , but in the remaining 6 , the amplitude of the $S$ wave had

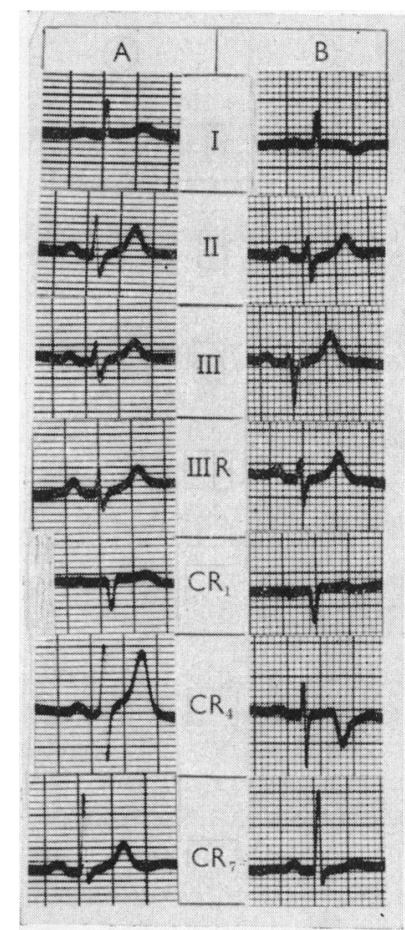

FIG. 5.-(A) $S$ waves in II and III in a man of 46 without cardiac pain suggested cardiac infarction, but plane S-T depression in I was not matched by a similar change in either lead CR4 or CR7. In (B), recorded 14 years later, signs of extension of the infarct were present 3 weeks after the onset of cardiac pain.

increased and usually in company with exaggeration of the associated significant cardiographic signs (Fig. 5, 6, 7, and 8).

These findings serve only to emphasize the greater likelihood of the appearance of material electrocardiographic signs, accepted as meaning a myocardial fault, when the amplitude of the $S$ wave is greatest in leads II and III. It was natural to find that the stability of S wave amplitude in lead III was greatest when the amplitude of $S$ in lead II was greatest (Table III).

Age Factor. In that the incidence of associated supporting electrocardiographic signs of a myocardial lesion, in the specific tracing which this paper examines, was related to some extent to the amplitude of the S wave in lead II, as also in lead III, this should not be accepted as meaning that the presence of a diminutive $S$ wave in these leads has less significance as an index of a myocardial lesion than the presence of a giant $S$ wave, because it may grow in time as the area of myocardial injury spreads. Observation over the years of subjects showing this sign should confirm it. 


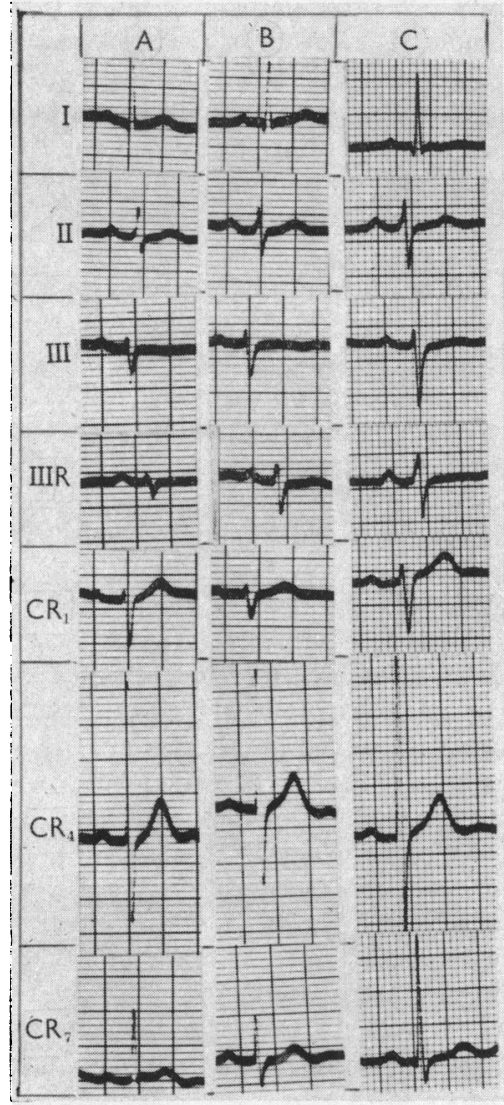

FIG. 6.-S waves in II and III in a man aged 53, without symptoms, were the only material signs of cardiac infarction in (A), and in (B) recorded 4 years later. The tracing (C) taken 6 years later and following the onset of cardiac pain, shows an increase in the size of the $S$ waves, a flat $T$ wave in lead $\mathrm{I}$, and a low and blunted T in CR7.

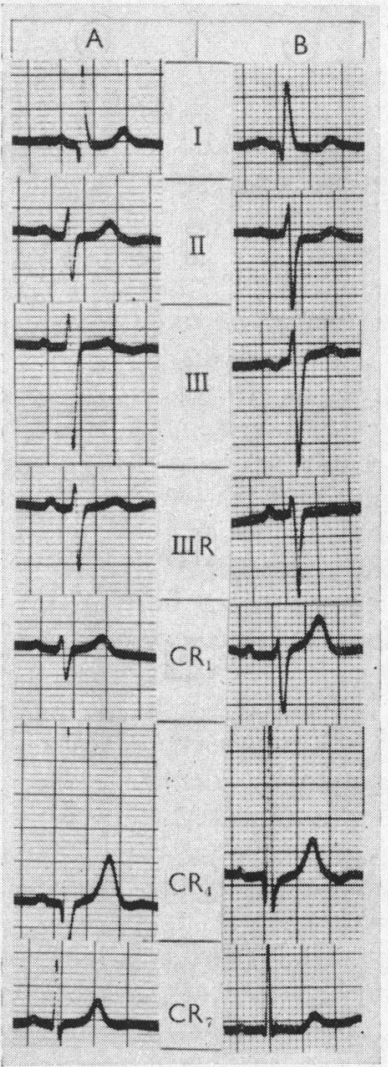

Fig. 7.-A deep S wave in leads II and III, and plane depression of the S-T segment in CR7, are the only abnormal signs in (A) from a man aged 75 without cardiac pain. In (B), taken 7 years later, though depression of the S-T in lead I has been added and the same change increased in CR7, cardiac pain was still absent.

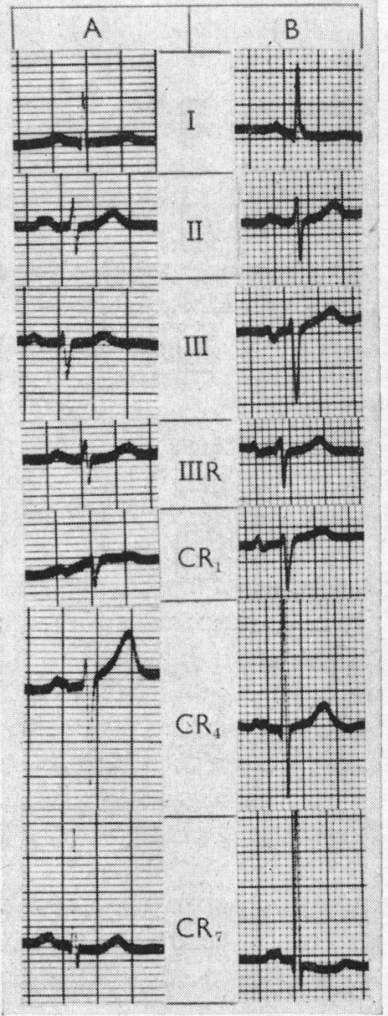

FIG. 8.- $S$ waves in leads II and III along with slight depression of the $S-T$ segment in leads I and CR7 in (A) suggested cardiac infarction in a man aged 65 without cardiac pain. When (B) was recorded 4 years later, cardiac pain had set in, and the record shows an increase in the size of the $S$ waves and greater depression of the $\mathrm{S}-\mathrm{T}$ in the two leads.
Support for this view comes from a consideration of the ages of those 17 patients in whom both cardiac pain and supporting electrocardiographic signs of myocardial disease were absent. With the exception of one aged 70 years, they were under the age of $57 ; 7$ of them were under the age of 25 years, and the mean age for the group was 35 years.

\section{SUMmaRY AND CONCLUSIONS}

A close scrutiny of the electrocardiogram in search of the lesser changes that stem from coronary arterial disease, once a need for emphasis, has now
TABLE III

TRUE AMPLITUDE OF $S$ WAVE IN LEAD III, COMPARED WITH AMPLITUDE OF S IN LEAD II

\begin{tabular}{c|c|c|c}
\hline $\begin{array}{c}\text { Amplitude } \\
\text { of } S \text { in } \\
\text { lead II }\end{array}$ & \multicolumn{3}{|c}{ Stability of S wave-amplitude in III } \\
\cline { 2 - 4 } & $\begin{array}{c}\text { Greatest } \\
(58)\end{array}$ & $\begin{array}{c}\text { Lesser } \\
(26)\end{array}$ & $\begin{array}{c}\text { Least } \\
(16)\end{array}$ \\
\hline $\begin{array}{c}\text { Greatest } \\
\text { (21) } \\
\text { Lesser } \\
\text { (37) } \\
\text { Least }\end{array}$ & 21 & 0 & 0 \\
(42) & 25 & 8 & 4 \\
\hline
\end{tabular}

Key to values represented by greatest, lesser, and least for the $S$ in leads II and III, respectively, is the same as in Tables I and II. 
become an accepted habitude. The need now is to examine others that lay claim to be numbered among them.

That a tracing in which an $S$ wave, absent in lead I, exceeds in amplitude the $R$ wave in leads II and III, indicates a myocardial lesion, has been shown to be true. What has not hitherto been established is whether the $S$ wave in these leads, in any amplitude, has the same significance.

This paper describes an investigation of 100 consecutive patients who presented with this electrocardiographic sign, patients who had attended for medical examination for diverse reasons. Patients with left ventricular hypertrophy from systemic hypertension, aortic valve disease, or mitral regurgitation, and instances of non-coronary myocardiopathy, were deliberately excluded from the series.

To test the competency of a small electrocardiographic deformity of common occurrence, in the detection of coronary arterial disease, is not easy, for in an uncomplaining subject, it can be accepted either as an incidental finding in health, or interpreted as the earliest manifestation of a myocardial lesion appearing way ahead of symptoms. Three criteria help to establish such a flaw as significant. First, a patient presenting it may be, or may become, subject to cardiac pain. Secondly, other signs, already accepted as proof of a myocardial lesion, may accompany the probationary sign. Thirdly, subjects presenting the cardiographic deformity may in the course of time develop undoubted clinical, electrocardiographic, and ultimately pathological evidence of cardiac infarction. A record of the exercise electrocardiogram cannot decide the significance of these small changes, for a negative test may be obtained when the collateral coronary circulation is functioning efficiently. Moreover, even the presence of pain, descriptively characteristic of cardiac pain, cannot by itself be accepted unequivocally as proof of a myocardial fault, in the absence of associated electrocardiographic signs to support the diagnosis. Indeed, greatest reliance has been placed on the presence of other abnormal features of the electrocardiogram in apportioning to the lesser sign its true value. Among the 100 patients who showed the specific electrocardiographic deformity submitted to inquiry, all save 18 showed such supporting signs in the tracing. In that the mean age of these 18 was 35 years, and that 7 of them were under the age of 25 years, the cautious opinion is justified that in them too the sign is likely to be significant, and that in the meantime it provides the lone evidence of a small and early myocardial fault.

The greater the amplitude of the S wave in lead II the greater the incidence of supporting electrocardiographic changes. Thus, when the $S$ was greater than $1 \mathrm{~mm}$., 51 out of 58 cases showed such changes compared with 31 out of 42 cases where the $S$ was $1 \mathrm{~mm}$. or less. The same applied to the amplitude of the S in lead III, and the stability of this wave-amplitude as tested through recording IIIR. Thus, when the $S$ wave was greater than $R$ in both III and IIIR leads, supporting electrocardiographic signs of myocardial involvement were present in 54 out of 58 cases, in 22 out of 26 cases where the $S$ was greater than $R$ in III but less than $R$ in IIIR, and in only 7 of the 16 cases where the $S$ was less than R in both III and IIIR leads; 7 of the 9 cases in this last group without supporting cardiographic signs were under the age of 25 years.

The investigation appears to have established that an S wave in leads II and III of the electrocardiogram, in any amplitude, when it is absent in lead I, indicates a fault in the myocardium.

Although it is likely that this specific electrocardiographic deformity by itself is the outward sign of early coronary arterial disease, since the ultimate health pattern of the individual who harbours it cannot be divined, it would be wrong to inform either patient, relative, or prospective employer of its existence. It should be known for what it is, namely a flaw limited at the time to a small sector of the myocardium, whose state in the years ahead cannot be predicted unerringly at the time.

\section{REFERENCE}

Davies, H., and Evans, W. (1960). The significance of deep S waves in leads II and III. Brit. Heart f., 22, 551. 